Concept Paper

\title{
Disaster Risk Reduction and Climate Change Adaptation - A Sustainable Development Systems Perspective
}

\author{
Tom R. Burns ${ }^{1,2, *}$ and Nora Machado ${ }^{2}$ \\ 1 Department of Sociology, Uppsala University, Uppsala 75126, Sweden \\ 2 Centre for Research in Sociology, University Institute of Lisbon, Lisbon 1649-026, Portugal; \\ noramachado@gmail.com \\ * Correspondence: tom.burns@soc.uu.se Tel.: +46-18-471-51-95
}

\begin{abstract}
This article considers the concepts of sustainability and sustainable development in relation to disaster risk reduction and climate change adaptation. We conceptualize sustainability from a social systemic perspective, that is, from a perspective that encompasses the multiple functionalities of a social system and their interrelationships in particular environmental contexts. The systems perspective is applied in our consideration and analysis of disaster risk reduction (DRR), climate change adaptation (CCA), and sustainable development (SD). Section 1 introduces briefly sustainability and sustainable development, followed by a brief presentation of the theory of complex social systems (Section 2). The theory conceptualizes interdependent subsystems, their multiple functionalities, and the agential and systemic responses to internal and external stressors on a social system. Section 3 considers disaster risk reduction (DRR) and climate change adaptation (CCA), emerging in response to one or more systemic stressors. It illustrates these with disaster risk reduction in the cases of food and chemical security regulation in the EU. CCA is illustrated by initiatives and developments on the island of Gotland, Sweden and in the Gothenburg Metropolitan area, which go beyond a limited CCA perspective, taking into account long-term sustainability issues. Section 4 discusses the limitations of DRR and CCA, not only their technical limitations but economic, socio-cultural, and political limitations, as informed from a sustainability perspective. It is argued that DRRs are only partial subsystems and must be considered and assessed in the context of a more encompassing systemic perspective. Part of the discussion is focused on the distinction between sustainable and non-sustainable DRRs and CCAs. Section 5 presents a few concluding remarks about the importance of a systemic perspective in analyzing DRR and CCA as well as other similar subsystems in terms of sustainable development.
\end{abstract}

Keywords: Systems Theory; multi-factor model; sustainable development; DRR; CCA

\section{Sustainability and Sustainable Development}

\section{Sustainability: Background and Definition}

The literature on the concepts "sustainability" and "sustainable development" is vast [1]. These influential concepts emerged out of political and administrative processes, not scientific ones. Like the concept of development itself, sustainable development has been a contentious and contested concept, not only with respect to controversies between advocates of capitalism and those of socialism and social democracy, but between industrialized and developed countries, or between modernization advocates and their diverse opponents. In other words, environmental issues have been added to earlier contentious issues. These have been and continue to be divisive, for instance between those who, on the one hand, advocate limiting or blocking much socio-economic development in order to protect or reclaim the environment and those who, on the other hand, stress 
the need of socio-economic development to alleviate poverty and inequality, if necessary at the expense of the state of the environment.

Historically, the linkage of sustainability and development has been, in large part, the result of global political and administrative processes and the diverse interests driving these processes. The term "sustainable development" was coined as a political-administrative term to bridge differences between developed and developing countries in the context of UN negotiations and resolutions. The UN World Commission on Environment and Development (hereafter, World Commission), chaired by Gro Harlam Brundtland (former Norwegian Prime Minister), produced an influential report in 1987, Our Common Future (World Commission [2]). The Brundtland Commission had been established by the UN in 1983 in response to growing awareness and concerns of the deterioration of the human environment and natural resources at the same time that developing countries were pushing for higher levels of economic growth (with the likelihood of increased damage to the environment). The Commission was to address the environmental challenge as it was intertwined with economic and social issues.

The Commission concerned itself with environment and growth/development as well as a number of related issues. The term "sustainability development" (SD) was intended to build bridges between the economic, ecological, and social areas of concern. Above all, the concept was meant to refer to development that meets the needs of the present generation without compromising (or jeopardizing) the ability of future generations to meet their needs (numerous other definitions have been proposed [1]; among others see [3-6]). It was intended to build bridges between, on the one hand, developed countries particularly concerned about issues of sustainability and, on the other hand, developing countries determined to industrialize and develop themselves economically and socially [2]. A precise definition of sustainable development, based on entirely technical or ecological criteria is not feasible; concepts such as "sustainable development" and "sustainability" are normative and political ones [5], much like "democracy", "social justice", "equality", "liberty", etc. rather than precise, scientific concepts (Sustainability and sustainable development differ in that the former refers to a complex of values/goals to be realized, while the latter refers to the process of societal change aiming at, and moving toward, sustainability goals).

As normative concepts, they are contested and part of struggles over the direction and speed of social, economic, and political initiatives and developments in the global context [7,8]. Similarly, DRR and CCA are also normative concepts This means that-unlike purely scientific concepts such as force, electric charge, negative feedback, complex social network-they provide policy orientation and a normative or moral "force" (Disaster risk reduction (DRR) is defined by UNISDR as the systematic development and application of policies, strategies, institutional arrangements, and practices to minimize vulnerabilities, hazards, and the unfolding of disaster impacts throughout a society [9]; Climate Change Adaptation (CCA) is defined by the IPCC as "adjustment in natural or human systems in response to actual or expected climatic developments or their effects, so as to moderate harm or to exploit beneficial opportunities" [10].)

Sustainability, as a normative and political concept, is used, among other things, to refer to a fair distribution of natural resources among populations of the world today as well as among different generations over time. It concerns also values and 'rights' to existence of other species as well as notions about how much environmental capital one generation should bequeath to the next [5]. In the language of policymaking, reference is often made to the three or more pillars or fields of sustainable development: effective and enduring normatively satisfying economic functioning and prosperity, social welfare and justice, political deliberation and decision-making, and environmental protection. The most difficult challenge is to determine how one combines and balances these in a sustainable manner, particularly since under many conditions they are contradictory: economic growth may be accomplished at the cost of environmental protection and conservation, or economic growth is sacrificed for the sake of increased public welfare and distributive justice.

The concept's power and also contentiousness relates to it bringing together these apparently contradictory environmental, economic, social and political imperatives. Harris [11] emphasizes that 
its contestation arises not only from the emphasis placed on diverse imperatives but from the difficulties encountered in their practical combination and realization.

The sustainability perspective calls for a complex systems model of society and the latter's multiple interactions with its physical and social environment [1]. In part, this is because sustainable development focuses our attention on multi-functionality and multiple-dimensional interactions.

\section{Social System Model}

Drawing on earlier work $([1,12,13])$, our point of departure is a model of complex systems (ecological as well as social) with which to characterize and analyze DRR, CCA, and SD, all of which are instances of complex systems. The model is based on a social science theory of dynamic, complex systems ([12-16]). After introducing the theory here, we apply it in formulating models applicable to complex, multi-faceted, dynamic systems: socio-technical systems such as adaptation subsystems and disaster reduction subsystems. Such systems are not only multi-dimensional but typically have multiple vulnerabilities to diverse hazards internally or externally generated [17]. The systems are subject to perturbation/change-due to external forces or internal processes. Their responses are usually non-linear, and not fully predictable (in part because there are unintended and unanticipated impacts), and, therefore, also not fully controllable.

Consider a complex social system with a population of social actors, rule regime(s) underlying social relationships and interaction patterns, resources (materials and technologies), multiple production processes functioning in their social and ecological contexts:

(1) Our perspective entails the following dynamics patterns: Complex "social systems" have multiple subsystems with multiple interrelated functionalities (economic, socio-cultural, educational, political, etc.). In complex systems a number of DRR subsystems as well as CCA subsystems are likely to be included designed to deal with particular stressors, for example, earthquakes, floods, spread of dangerous diseases (or their vectors). DRR and CAA stressors are addressed by one or several selected subsystems (in many cases, they may be largely local in character).

(2) Functioning systems are subject to external and internal stresses of varying degrees of hazard. Some stressors may result in systemic performance failings, possibly disasters. That is, failure to avoid some hazardous stressors or to regulate/control/block them results in malfunctioning and even substantial damage to the system, the people involved, the property, and essential resources, in short, systemic disaster.

(3) Our systems approach views agents as acting within (embedded in) and also upon systems (performing in them as well as adapting and transforming them through multi-level governance arrangements). Agents in any given system (and also possibly external agents) make judgments about adaptation and risk reduction measures as well as sustainability measures. They assess performances, risks, hazards, vulnerabilities, adaptation and sustainability needs. This entails normatively oriented judgment and risk logic(s).

(4) Responses to stressor are typically in the form of built-in algorithms and procedures that are activated as well as agent-responses (through monitoring, innovating, taking actions to regulate, ban, or avoid the stressors). Multiple agents are typically involved, managers, experts, operatives who make use of appropriate materials and technologies, and operate according to a design.

The systemic model enables a robust conception of sustainability and sustainable development. As we have seen, it identifies hazards and opportunities for DRR and CCA as well as risk reduction for other challenges. DRR (and CCA as well as other systems or subsystems) entail constructions (or re-constructions) of subsystems for the purpose of response to stressors and involve such operations as "avoiding", regulating/blocking, reducing vulnerability, transforming the stressors and/or the social system as a whole (see Table 1). 
Table 1. Agential and Systemic Response to Stressors.

\begin{tabular}{ll}
\hline I & $\begin{array}{l}\text { Powers and capabilities are mobilized to reduce exposure or contact; withdrawal, migration, } \\
\text { temporary or seasonal retreat. }\end{array}$ \\
\hline II & $\begin{array}{l}\text { Powers and capabilities mobilized to partially block, regulate, countervail (for instance, } \\
\text { building dams, walls or other barriers, or canals, or eliminating a disease through } \\
\text { vaccination) }\end{array}$ \\
\hline & $\begin{array}{l}\text { Powers and capabilities are mobilized to adapt and transform the system or its subsystems: } \\
\text { construction of waterways and canals combined with irrigation, elimination of a population } \\
\text { of parasites or threatening animals, or eliminating disease-vectors i.e. drainage of mosquito } \\
\text { breeding areas; establishing or reforming educational and research subsystems, etc. }\end{array}$ \\
\hline
\end{tabular}

The concerns here include restructuring or transforming a given system in order to adapt to or to overcome stressors such as climate change or other global environmental change (GEC), reducing exposure to hazards, reducing vulnerability, reducing or repairing damages to the system or system components effectively. System adaptation/transition may accomplish then a reduction in a stressor or vulnerability to it. A systems perspective enables us to identify social structural, political, and agential factors relating to system stressors such as destruction of infrastructure, weather changes, new disease vectors, and other vulnerabilities to them - and how major agents in a system respond to these with strategies to overcome-or perhaps fail in their efforts. In particular:

- Multiple powerful agents - those controlling essential resources and expertise in the systemmust be mobilized and coordinated to address the hazards and vulnerabilities (and to overcome barriers and opposition to adaptation and systemic transition).

- That is, mobilizing and coordinating agents gain access to essential resources, authorities experts, stakeholders, etc. to address system stressors.

- There are typically multiple adaptations to one or more stressors: for instance, in the case of climate change, flood control response may be combined with retrofitting buildings to be morobust or less vulnerable to moisture and mildew.

Thus, we emphasize not only the importance of agents - and their culture, capabilities, and access to resources-but also the complex social systems in which agents interact and upon which they operate. A complex social system has populations of social actors, rule regimes of social and cultural structures, resources (materials and technologies), and multiple production processes in a social and ecological context (see the representation in Figure 1). 


\section{SOCIAL AND ECOLOGICAL CONTEXT}

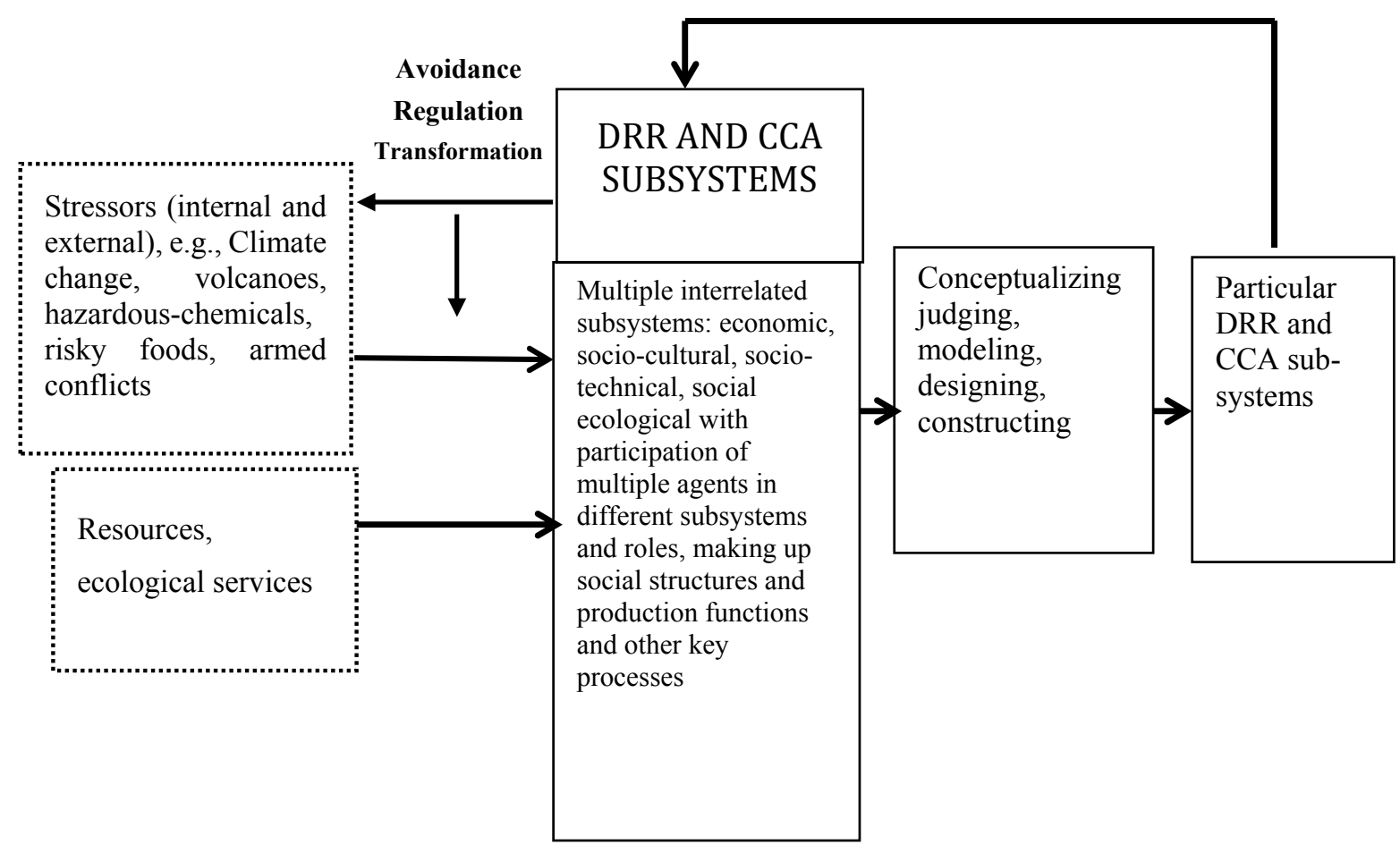

Figure 1. Multi-factor model of social system response to stressors.

The systems model enables us to systemically describe and analyze such constructed subsystems as those of DRR and CCA (Section 3). These subsystem constructions were launched and developed by agents in order to deal with climate change and other system challengers. But many system functions do not relate directly to climate change or DRR. Sustainable development entails a global perspective that encompasses multiple subsystems, which are differentiated and have diverse functionalities.

\section{Case Studies of Response to Stressors}

For our purposes here we consider two types of stressors (which may overlap): disaster with the action of DRR and the hazard influencer of climate change with the action of CCA - that is, actors' responses to these. Section 3.1 presents two DRR cases, one concerning food security, the other concerning chemical security. The cases are based on EU policy research; the methods were multiple: interviews with informants and experts, documents and research materials, and reports in the mass media. Section 3.2 presents CCA cases, one about the island of Gotland, Sweden, the other about the Gothenburg Metropolitan Area (GMA). Both of these cases are based on analyses of official documents, research reports, and mass media coverage as well as personal experience and observation (living on Gotland and in Gothenburg).

\section{1. $D R R$}

Reducing exposure to hazards, lessening vulnerability of people and property, effective management of land and the environment, and improving preparedness for adverse events are all examples of disaster risk reduction [18,19]. Natural and man-made hazards-and societal vulnerabilities to these-are reduced through proper disaster management policy, material and institutional development policies and constructions. As a result of failures to introduce or maintain disaster management policy and practices, disaster risk and disaster losses are likely to increase in the case of hazardous systems [17]. 
Highly risky isaster systems (whether due to technologies, the complexity of socio-technical systems, ecological contexts, or the participating agents) are those which have the potential (a certain (even if very low) likelihood, to cause great harm to property and people involved, partners or clients, third parties, other species, and the environment. Some risky systems have catastrophic potential in that they are capable in case of a performance or regulatory failure to kill hundreds or thousands, wiping out species, or irreversibly contaminating the atmosphere, water, and land.

DRRs make up systems, typically complex, with particular measures or operations to reduce risks from external stressors and/or internal stressors (through monitoring, testing, and actions to ban or regulate); multiple agents are involved, managers, experts, operatives, and use is made of appropriate materials and technologies, operating according to a design. There are production processes, governance and regulative processes within the system and also externally. Examples are nuclear power facilities, flight control systems, chemical regulatory systems, food regulatory systems, renewable energy sources which may contribute to, for instance, sustainability and climate change adaptation but entail new risks, or limit new forms of CCA and DRR: thus, tigers/wolves and other predators which contribute to biodiversity may increase risks of "accidents" with livestock and children; policies and programs to reduce hazards of and adapt to climate change challenges may increase risks of economic and political threats.

Two significant instances of DRR, which we have investigated, relate to EU policymaking and regulation regarding food and chemical safety. Although these are both large sectors with multiple stressors and disaster risks, they cover only narrow fields of societal stressors and vulnerabilities.

Box 1 explores food safety governance as a DRR topic, through examining reduction or control of disease or disease vectors (humans, animals) related to food ("Safe Food as A Public Good") [20].

Box 1. Disaster risk reduction (DRR) regarding food in the EU.

OVERVIEW: As background to this particular stressor and transformation in governance, numerous "risks" and "technical" problems had already been noted during the deregulation associated with the establishment of the EU "internal market" in food and agricultural products. Diverse problems and issues associated with food contamination and safety called for the development of new regulations at the European level. Following the "mad cow disease" scare and other publicly recognized regulatory failures relating to food in the 1980s and 1990s, EU Food governance was redefined as food safety (prioritizing the healthy and safety aspects of food as a public good over "food as a commodity" [20]. New institutional arrangements were implemented: responsibility for food safety policy was moved from DG Industry (later DG Enterprise) to DG Health and Consumer Affairs, and a food safety authority, European Food Safety Authority (EFSA) was established (January 2002). Expertise was recruited on the EU level to address problems of contamination and disease, and EU level monitoring and regulation was launched. The EU used its centralized powers to establish an entirely new food security governance system.

\begin{tabular}{|l|l|}
\hline $\begin{array}{l}\text { Issue or problem threatening } \\
\text { health and environmental } \\
\text { disasters }\end{array}$ & $\begin{array}{l}\text { BSE and dioxin threaten health in the 1980s. } \\
\text { Also, systemic threat to the concept of the EU integrated market as EU } \\
\text { conflicts emerged in response to the threats and several EU member states } \\
\text { blocked or threatened to block food from another state, contrary to EU treaties }\end{array}$ \\
\hline $\begin{array}{l}\text { Drivers of change: key } \\
\text { agents respond to stressors } \\
\text { with reform actions }\end{array}$ & $\begin{array}{l}\text { DG Enterprise, Commission's public health administration; several key } \\
\text { member states (in particular, France, Germany) }\end{array}$ \\
\hline Main opposition agents & UK and Belgium governments, relevant agricultural interests and ministries \\
\hline Modes of change & $\begin{array}{l}\text { Crisis driven. Relatively rapid response but part of a longer-term complex } \\
\text { learning process relating to EU food production, its distribution and } \\
\text { guarantee of safety. }\end{array}$ \\
\hline Paradigm shift & $\begin{array}{l}\text { From framing food as market commodity to food as health and security issue. } \\
\text { Organizational/institutional change: Creation of EFA (food authority), } \\
\text { creation of DG Health and Consumption as a powerful commission agent }\end{array}$ \\
\hline Discourse Shift & $\begin{array}{l}\text { From food as market commodity to food as a safety issue ("safe food as a } \\
\text { public good"). "EU authority" established in the area of food regulation } \\
\text { replacing national governance and authoritative discourses }\end{array}$ \\
\hline
\end{tabular}


Box 2 presents chemical security governance as a DRR topic, through reduction of levels and exposures to hazardous chemicals that threaten human health and the environment [20].

Key agents in the cases mobilized sufficient powers to impose safety controls, to regulate, and even to ban and thus successfully reduce disaster risks. Note the multi-level character of these two cases. Global EU legislation and monitoring, while implementation takes place at the member-state or national level.

Box 2. DRR regarding chemicals in the EU.

OVERVIEW. Rachel Carson's Silent Spring [21] warned of the dangers to all natural systems from the misuse of chemical pesticides such as DDT (an abbreviation for dichlorodiphenyltrichloroethane, a colorless insecticide that kills on contact; it is poisonous to humans and animals when swallowed or absorbed through the skin and is widely banned), and questioned the scope and direction of modern science. The work contributed to initiating the contemporary environmental movement. Thousands of organizations were over time established and became involved in addressing the dangers of many chemicals and their threat to human health and environment. UN organizations and OECD were significantly engaged in the development. The "Stockholm Declaration", formulated in 1972, called for International action on a global scale against chemical pollution and the threat of chemicals to health and the environment. In 1990, the EU launched a radical regime of regulation designed to cover a major part of all chemicals (substances of either high concern or manufactured or imported over 1000 tonnes). The law replaced a patchwork of some 40 legislative instruments in force at the time. The European Chemical Agency (ECHA) was established in 2007. Thousands of substances (approximately 30,000 expected) already on the market would be assessed and eventually subject to authorization. The burden of proof of chemical safety would now lie with the producers, and no longer with regulators or consumers. Dangerous chemicals could be readily banned - or if their value to society were judged to be very high they could be allowed but under very tight controls, and a safer alternative would be expected in the future.

The REACH law (Registration, Evaluation, Authorization, and restriction of CHemicals) came into effect in June, 2007 following a process involving almost a decade of debate, mobilization, struggle, and negotiations between the Commission, the Council of the European Union, the EU Parliament, industry, labor unions, environmental, consumer and animal rights NGOs, and others (see below).

Issue or problem threatening health and environmental disasters including the "silent hazards" such as in the case of asbestos

Many chemical threats to human health and environmental health not sufficiently recognized and regulated.

\begin{tabular}{|c|c|}
\hline & \\
\hline $\begin{array}{l}\text { Drivers of change: key agents } \\
\text { respond to stressors with } \\
\text { reform actions }\end{array}$ & $\begin{array}{l}\text { Change in international context with the emergence of influential NGOs } \\
\text { and environmental movements (even "political" such as the Green } \\
\text { parties). Several new EU member states such as Sweden, Austria and } \\
\text { Finland prioritized a stringent EU regulation of chemicals. DG } \\
\text { environment led by a major Swedish politician (Margot Wallström), and } \\
\text { the environmental movement (Green political parties and NGOs) pressed } \\
\text { for far-reaching legislation. }\end{array}$ \\
\hline Main opposition agents & $\begin{array}{l}\text { European chemical industry (and the US and Japanese industries). UK, } \\
\text { French, and German top political leaderships. The USA also lobbied } \\
\text { against, in particular in EU member states themselves. }\end{array}$ \\
\hline Modes of change & $\begin{array}{l}\text { Attention increasingly focused on widespread risks (chemicals in the } \\
\text { environment, in human bodies, in pregnant women, in children) and on } \\
\text { European inconsistencies in regulating some chemicals such as asbestos. } \\
\text { Scientific indications and growing public awareness that only a few of the } \\
\text { most dangerous chemicals were recognized and adequately recognized. } \\
\text { Scientific and technical research along with legal preparations were } \\
\text { launched for far-reaching legislation, policy shifts, and institutional } \\
\text { innovation and development. }\end{array}$ \\
\hline Paradigm shift & $\begin{array}{l}\text { From relatively low and sporadic regulation to a system where all } \\
\text { significant chemicals would be assessed for safety. Creation of ECHA to } \\
\text { monitor and sanction compliance. The burden of proof of safety or low- } \\
\text { risk is the responsibility of the producers, not the consumers or } \\
\text { government. Costs of determining low risk fall upon the producers and }\end{array}$ \\
\hline
\end{tabular}




\begin{tabular}{|l|l|}
\hline & $\begin{array}{l}\text { suppliers. Chemicals deemed unsafe for humans and the environment are } \\
\text { subject to ban. Some exceptions may be made temporarily. }\end{array}$ \\
\hline Discourse Shift & $\begin{array}{l}\text { From chemicals as all "good" to chemicals as potentially health and } \\
\text { environmental hazards and requiring "systematic regulation" -- as } \\
\text { opposed to "market freedom". European integrated authority to replace } \\
\text { member-state authority. }\end{array}$ \\
\hline
\end{tabular}

\section{2. $C C A$}

Climate change is characterized by, among other things, uncertainty about its future trajectory, its phases and timing and about potential impacts and non-containability within existing borders of jurisdiction [22] (p. 2). Examples of climate change stressors are changed rain intensities, altered precipitation patterns such as clustering or longer rain duration, runoff following snowmelt in combination with rain.

Examples of climate change adaptation are the introduction or development of infrastructures to reduce associated peak flows and flooding consequences in a given environment, development of new designs for built environments against moisture and flooding, development of more effective urban drainage systems, particularly as on the Swedish West Coast (Gothenburg and Malmo) where higher sea levels are likely to be combined with heavier rainfalls resulting in flooding of coastal and low land areas, with likely damage to infrastructures and buildings as well as threat to human life.

In general, key agents in social systems "adapt" (withdraw or change behavior/habitat) to prevent or avoid certain hazards, disasters (losses, damages), among others, climate change stressors. Even DRR is a form of "adaptation to",

- Disappearance of or threat to the group's/community's island or coast, and, construction of walls - Retrofit house because of more extreme weather, increase of rain and moisture in the area

- Educate and vaccinate in response to new disease vectors (ticks, mosquitoes carrying malaria...) emerge and adapt by educating people about the threat, precautions to take, and conducting campaigns.

Many disasters from climate change can be prevented. Buildings can be constructed to effectively survive increased humidity and flooding. Infrastructures (dams, canals, causeways, other barriers) can be constructed and integrated with ecosystems to limit flooding and erosion.

On many vulnerable coasts - where coastal erosion is occurring - those living there construct barriers against flooding and erosion. In Sweden, for instance, the threat of extreme rainfall and low land flooding has led to the development of methods to reduce or regulate peak flows and flooding consequences: (1) retreat (this means moving populations (human and animals) and infrastructure and other built environments, e.g., movement to safer grounds; (2) defend (defending against the stressors, e.g., to protect an urban area or lowland through flood defense, e.g., a wall (reducing levels of risk combined with cost minimization); (3) proactive response to, for example, rising sea levels through new construction in locations expected to be secure.

In many parts of the world, substantial floods occur regularly for millions of people who live in the low-lying riverine islands and coastlines. When floods occur, households often flee, if relevant giving their cattle to friends and neighbors to look after while they recover from flooding. In many coastal regions people use concrete blocks and trees such as mangrove trees to provide simple erosion protection and stilt houses to reduce flooding risks. In dry or semi-arid region, withdrawal is also a common response. For instance, water is critical in Tahova, a dry land region of Niger. Crops are difficult to grow in the dry season, so men migrate to the cities for work. Historically, water has also been stored or channeled from distant areas.

\section{Case 1: Gotland, Sweden Responding to Climate Change}

The Baltic island of Gotland is expected to be (and has already found itself becoming) subject to significant CC stressors, above all higher levels of precipitation and its multiple impacts as well as new disease vectors and diseases [23]. Reponses have been disease campaigns (including vaccination) 
to deal with the spread through ticks of borrelia and tick-borne encephalitis (TBE) and retrofit of buildings to deal with greater moisture (and coastal erosion). Planning and educational programs have been established. The significance of climate change for the island is widely recognized at the local (municipal), regional (Gotland region), and national levels. Like Gothenburg it is trying to move beyond the thinking of climate change adaptation and to envision a "sustainable Gotland" by promoting green (renewable) energy (already there are 170 windmills producing 380 gwk meeting $40 \%$ of the island electricity needs); the Island has an integrated recycling system which, among other things, produces biogas for public transportation; a desalination plant is being constructed; new kinds of nature tourism is being developed (tourism is a major economic sector on Gotland along with agriculture); there are restrictions on new building construction in coastal areas at heights under 2 meters over sea level; much attention is being given research and education because of major gaps in knowledge and policy experience confronting Gotland today.

Responses to climate change can vary greatly, depending on conceptual models, material resources, leadership, institutions and culture. The large (for Sweden) metropolitan area of Gothenburg suggests some of this and also points up that Gothenburg, like Gotland, is increasingly thinking in terms of sustainability rather than climate change adaptation and disaster risk reduction.

\section{CASE: Gothenburg Metropolitan Area [22]}

Climate change in the Gothenburg area threatens with increased flooding, slides, erosion, new diseases and disease vectors. Gothenburg Metropolitan area (GMA)-expected to be the part of Sweden most affected by the impacts of climate change-is addressing and acting upon relevant issues of climate change adaptation. This has been done within the framework of Sweden's Planning and Building Act which puts responsibility with local governments for dealing in the "common interest" of climate adaptation.

Gothenburg has developed a perspective and strategy for an environmental (and sustainable development) program as opposed to a purely climate program. The city stresses that climate work needs to be coordinated and guided toward long-term sustainability; climate need to be considered in the context of multiple environmental challenges and the measures to deal with them.

The stress then is on a broad systemic approach extending across multiple societal areas essential to sustainability: energy, transport, water supply regulation, building and infrastructure, education, consumption, social planning.

To encompass the totality of the challenge:

- "sustainable Gothenburg" has become a key normative public concept.

- A concept of sustainability relevant to the city, the "3-river city", has been developed. Among other things, this entails changing standards of expected flood levels and developing plans and programs to deal with expected impacts such as flooding, slides/erosion and loss or contamination of freshwater supply. In restructuring waterways and building barriers, there is both climate change adaptation and disaster risk reduction; regulating the water levels of the 3 major rivers is also both CCA and DRR.

- A green construction programme involves designating locations of building (LAFE) safe from flooding and slides for the purpose of authorizing building permits. The island Tjorn recommended a LAFE above the average sea water level for all buildings and infrastructures with vital societal functions and for all new buildings and transport lanes. Several municipal masterplans require geotechnical stability investigations relating to slides and erosion as precondition for detail planning and building permits.

- There is ongoing construction, operation, and maintenance of infrastructure to reduce climate and environmental impacts.

- Gothenburg has been orienting itself to sustainability-conscious consumption including climate conscious consumption (and to reduce climate impact of food production and transportation). This entails, among other things, reducing the purchase of resource-intensive goods.

- Waste is to be reduced and the current high level of recycling developed further. 
- Conducting research on issues, strategies, and consequences of sustainability and climate change adaptations, for instance, economic analyses of the costs (damages) from climate change versus the costs of measures to adapt and to prepare.

The case of Gothenburg, Sweden (see Box 3) illustrates the pertinence of placing CCA within wider sustainability contexts.

Box 3. Climate change adaptation (CCA) extended to sustainability issues in the Gothenburg Metropolitan area.

OVERVIEW [22]. Climate change in the Gothenburg area threatens with increased flooding, slides, erosion, new diseases and disease vectors. Gothenburg Metropolitan area (GMA) expected to be the part of Sweden most affected by the impacts of climate change -has been addressing and acting upon relevant issues of climate change adaptation. This has been done within the framework of Sweden's Planning and Building act which puts responsibility with local governments for dealing in the "common interest" of climate adaptation. GMA has launched a variety of policies and institutional response to actual and potential climate change stressors. In the course of conducting investigations and launching projects GMA developed a perspective and strategy for an environmental-and a sustainable development-program as opposed to purely climate programs. GMA emphasizes that climate work needs to be coordinated and guided toward long-term sustainability; climate need to be considered in the context of multiple environmental, economic, and social challenges and diverse measures to deal with them.

\begin{tabular}{|c|c|}
\hline $\begin{array}{l}\text { Issue or problem } \\
\text { threatening health and } \\
\text { environmental disasters }\end{array}$ & $\begin{array}{l}\text { Examples of climate change stressors are changed rain intensities, altered } \\
\text { precipitation patterns such as clustering or longer rain duration, runoff following } \\
\text { snowmelt in combination with rain, resulted in increased flooding, slides, and } \\
\text { erosion. There have also emerged new diseases and disease vectors. }\end{array}$ \\
\hline $\begin{array}{l}\text { Drivers of change: key } \\
\text { agents respond to } \\
\text { stressors with reform } \\
\text { actions }\end{array}$ & $\begin{array}{l}\text { Municipal political leadership, public energy companies, insurance companies, } \\
\text { research communities, Green Party, Green NGOs (Greenpeace and local } \\
\text { environmental groups) }\end{array}$ \\
\hline Main opposition agents & $\begin{array}{l}\text { After considerable flooding experience, there was very little opposition in GMA. } \\
\text { But typically municipalities in the region compete for resources. Issues of } \\
\text { administrative jurisdiction and resource scarcities and competition for resources } \\
\text { are key "opposition" or constraining factors. }\end{array}$ \\
\hline Modes of change & $\begin{array}{l}\text { Disaster driven initially; but also reports and experiences of disasters from similar } \\
\text { areas in Sweden and abroad. Examples of climate change adaptation in } \\
\text { Gothenburg are the introduction and development of infrastructures to reduce } \\
\text { associated peak flows and flooding consequences in the local environment, } \\
\text { development of new designs against moisture and flooding for built } \\
\text { environments, development of more effective urban drainage systems, } \\
\text { particularly since on the Swedish West Coast (Gothenburg and Malmo) higher sea } \\
\text { levels are likely to be combined with heavier rainfalls resulting in flooding of } \\
\text { coastal and low land areas, with probable damage to infrastructures and buildings } \\
\text { and threat to human life. } \\
\text { Among other things, this entailed changing standards of expected flood levels and } \\
\text { developing plans and programs to deal with expected impacts such as flooding, } \\
\text { erosion, and slides as well as loss or contamination of freshwater supply. In } \\
\text { restructuring waterways and flood barriers, there is both climate change } \\
\text { adaptation and disaster risk reduction; regulation of water levels of the } 3 \text { major } \\
\text { rivers is also both CCA and DRR. } \\
\text { Broad comprehensive programmes, integrated strategies, characterize } \\
\text { Gothenburg's response to the disaster threats of climate change (DRR). In addition, } \\
\text { there are pressures for regional "socio-economic growth", protection of coastal } \\
\text { areas for recreation and leisure, promotion of GMA's role as the logistic centre of } \\
\text { the Nordic Region. } \\
\text { To effectively avert the impact of flooding, slides and erosion and to secure GMA's } \\
\text { freshwater supply, governance and coordination arrangements are being } \\
\text { developed to encompass two nations, four regions and a substantial number of } \\
\text { local governments. These governance challenges compound problems of gaining }\end{array}$ \\
\hline
\end{tabular}




\begin{tabular}{|l|l|}
\hline \multirow{5}{*}{ Paradigm shift } & $\begin{array}{l}\text { acceptance and legitimacy for large-scale plans to adapt appropriately to the } \\
\text { expected impact of climate change [22]. }\end{array}$ \\
\hline $\begin{array}{l}\text { Gothenburg has developed a perspective and strategy for an environmental and } \\
\text { sustainable development program as opposed to a purely climate change } \\
\text { program. The city is stressing that climate work needs to be coordinated and } \\
\text { guided toward long-term sustainability; climate need to be considered in the } \\
\text { context of multiple environmental, economic, and socio-political challenges and } \\
\text { the measures to deal with them. Issues of a sustainable economy for GMA, } \\
\text { education (for instance, sustainable-conscious consumption), relevant research, } \\
\text { sustainable water supply regulation, and new transportation conceptions. The aim } \\
\text { is to develop a conceptualization and institutional order for sustainability relevant } \\
\text { to GMA. }\end{array}$ \\
\hline $\begin{array}{l}\text { Discourses emerged about climate change and its meaning for MGA in response } \\
\text { to increasingly serious flooding and erosion problems. But over time the } \\
\text { discourses have not only been about CCA but about sustainability issues: the } \\
\text { future of the local economy, energy, transport, water supply regulation, building } \\
\text { and infrastructure, education, consumption, social planning, among others. } \\
\text { "Sustainable Gothenburg" has become a key normative public concept. }\end{array}$ \\
\hline
\end{tabular}

\section{Sustainable Development as a Societal Development System}

\subsection{CCA and DRR are Only Partial Systems}

Sustainability judgments, designs, institutional arrangements, and developments would optimally include (or embed), among other things, appropriate and satisfactory CCA as well as appropriate and satisfactory DRR. System sustainability is multi-dimensional and with defined standards that surpass "sufficient adaptation" or "sufficient disaster risk reduction". As suggested above, the latter are only partial. In contrast to sustainable development arrangements where multiple functionalities and the interrelationships of multiple "pillars" are built in conceptually and practically, CCA and DRR models tend to leave out or leave implicit a number of key functionalities, for instance, agential aspects (training and education, the necessary professionalism), reliable appropriate materials and technologies, and the sustained over time budgeting (private and/public). These factors must be included in a broad or systemic perspective, as in sustainability models, in ways that are not inherent to DRR or CCA subsystems. Pelling [24] also stresses such limitations of CCA and the need to take into account political, institutional, cultural, and ecological factors; see also [25].

In the conceptualization of CCA and DRR, in contrast to sustainability's multi-functionality conception, that typically take as a point of departure sustained budgeting levels, the support and legitimation of key societal actors, and the education of experts to manage and operate disaster risk reduction apparatuses - that is, the economic, socio-cultural, and political bases for financing and operating the systems. In a sustainability perspective these are taken into account explicitly.

The argument here suggests that CCA and DRR arrangements may or may not be sustainable over the medium-to-long-run. This may be for economic reasons, ecological/natural resource constraints, or socio-cultural forces (refusal of the population to sufficiently change life-style or make necessary institutional and economic changes (replacing fossil fuels with renewable energy sources and controlling pollution and environmental degradation, among others).

Although CCA and DRR are only partial systems, they may relate to one another in systemic terms $[26,27]$. But they are not necessarily compatible with sustainable development, as we now discuss.

\subsection{Possible Incompatibility of CCA and DRR Systems with Overall Social System Sustainability}

As suggested above, DRR and CCA may not be compatible with sustainable development, in that their scope may be far-too-narrow, ignoring a number of key dimensions of sustainable development in the social systemic context such as increased reliance on renewable energy, biodiversity support, and chemical pollution reduction. At the same time, policymaking agents may 
accept disaster risks (and reject adapting to climate change or other threats because of lack of resources, or poor judgment of cost/benefit imbalances or priorities elsewhere).

Or, as pointed out below, it may be a matter of prioritization or practices of risk-taking. In responding to stressor(s), agents may prioritize broad sustainability over particular disaster risks including those influenced by climate change, like sacrificing a leg for survival of the rest of the body. Or vice versa, one may risk the social system as a whole to save an important part of the system; for instance, the system's elite or its particular social structure (e.g., an apartheid system). Or, for the sake of technological advancement, one takes unknown risks with Genetically Modified Organisms in the context of $100 \%$ sustainable food supply. In these cases, CCA could be said to trump sustainability from the perspective of a high risk-taker. Thus, one may succeed in accomplishing DRR and CCA without achieving or maintaining medium-to-long-run sustainability. Consequently, successful DRR (possibly involving CCA, or not) may accomplish (immediate objective(s)) but may be unsustainable over time or over an extended space-in short, they are unsustainable subsystems. Unsustainability may be caused by (1) insufficient resources (including technologies); (2) agents' insufficient knowledge and/or capabilities; (3) insufficient coordination and effective governance (organizational); (4) insufficient socio-political legitimacy and political support.

\subsection{DRR and CCA Should Be Subjected to Sustainability Standards, Discourses, and Judgments}

The DRR and CCA subsystems are judged to be sustainable if and only if (1) essential inputs into these subsystems are sustainable (or replaceable with sustainable factors when used up); (2) subsystem outputs do not undermine, block, or interfere with the sustainability of other subsystems or with the social system as a whole. That is, a given subsystem in its interactions with other subsystems may produce disaster risks (or increases in disaster risks) or produce developments that undermine, block, or interfere with sustainability conditions and mechanisms.

In general, from a holistic, societal perspective, DRR and CCA can be viewed and assessed in relation to the societal multi-functionality and long time scale of sustainable development. Sustainability incorporates capacities to deal with such potential systemic disturbances as climate change (as well as other hazardous global changes), either through prevention or avoidance and/or adaptation.

Several key points in this part are: (1) One may accomplish disaster risk reduction which in the medium to long run is not sustainable in terms of ecological, economic, or socio-political dimensions; (2) One may also have adaptation with respect to a stressor $X$, for instance climate change, without system or even subsystem sustainability; (3) DRR and CCA may be pursued separately or pursued as part of an overall initiative to adapt to particular climate change impacts in such a way as to reduce disaster risk; (4) DRR and CCA - while important sources of conceptual and methodological toolsmay lead to non-sustainable judgments and developments. In other words, improvements in DRR and CCA may not be sustainable over the long run because of their unintended or unanticipated impacts on key sustainability dimensions. (5) Note that the systems model alerts us and enables us to analytically differentiate DRR, CCA, and sustainability development. It is argued here that DRR and CCA should and can be related to the medium term- long-term goals of sustainable development. (6) In general, the factor of sustainability trumps DRR and CCA in terms of impact assessment and design, but there are other considerations as discussed below.

\subsection{Distinctions between Sustainable and Non-Sustainable DRR and CCA}

DRR for a particular hazard (e.g., volcanic eruption, earthquake, soil erosion, salination of the soil) may or may not be sustainable in the long-run. It may be unsustainable because, for instance:

- The DRR action or its socio-technical system makes use of non-renewable, non-replaceable resources

- Or the DRR system blocks necessary adaptation of the more encompassing social system, for instance by draining away resources essential to the sustainability of the larger system. As a result of this systemic non-sustainability, the DRR sub-system will fail to be maintained over the medium to long run. 
- In the prevailing socio-cultural and economic perspective, people are unwilling to make the sacrifices for DRR, for instance, they are willing to accept the risk of a volcano or earthquake, or the rising seas.

In sum, sustainability developments, judgments, designs, and institutional arrangements may include (or embed), among other things, appropriate and satisfactory CCA placed within appropriate and satisfactory DRR. System sustainability is multi-dimensional and with defined limits that surpass "sufficient adaptation" or sufficient DRR. The latter are only partial.

On the other hand, a "necessary" CCA or DRR infrastructure may or may not be sustainable over the medium to long-run. This may be for economic reasons, ecological/natural resource constraints, or socio-cultural forces (refusal of the population to sufficiently change life-style or to make necessary institutional and economic changes (for instance, shifting from fossil fuels to renewable energy sources).

\section{Concluding Remarks}

The sustainability or sustainable development perspective provides a systemic view, indicating the complex interdependencies among essential subsystems to human welfare and survival. Societal sectors or specialized subsystems like DRR or the CCA subsystem within it are insufficiently comprehensive when viewed from the perspective of a sustainability framework; they do not explicitly take into account the systemic economic, socio-cultural, and political factors in societal survival and even the question of the availability of long-term resources for CCA and DRR subsystems themselves (long-term resource availability and sufficient prioritization of the resources in competition with other demands).

The conception of sustainable development orients us not only to ecological factors and the interaction of the ecological, and the social. It also orients us to the economic conditions and processes, the essential conditions for financing and maintaining subsystems or programs of DRR as well as CCA; and it orients us to consider socio-cultural conditions essential to policy legitimation and the maintenance of societal support and a readiness to aim for wider sustainability. Sustainable development is concerned about social systems as a whole and the long-time scale. A complex systems perspective encompasses then not just functionality and simple cost-benefit issues but multifunctional and multi-dimensional sustainability: it considers that a sub-system may contribute not only to ecological sustainability but to the economy, to cooperation and coordination, and other governance mechanisms as well as legitimacy socio-cultural integration, and political order.

And, as we have seen, a system may be sustainable and include its climate change adaptability (as well as perhaps other environmental change adaptability) within its DRR capacity as well as DRR capacity beyond CCA. But, as indicated in Section 4, the designs, realizations and practices of CCA and DRR subsystems should be incorporated into a sustainable development model, its standards and values, discourses, plans, and institutional arrangements. Failure to do this would mean, in general, that DRR subsystems and CCA - and the social system in which they are embedded - may not be sustainable or only precariously sustainable (because vulnerable to particular internal and/or external stressors). Thus, as discussed earlier in the chapter, a well-functioning DRR subsystem or a well-functioning CCA subsystem may be non-sustainable for long-term economic reasons, or for socio-cultural or political reasons; or indirectly, the DRR or CCA subsystem drains away essential resources or interferes with key systemic mechanisms essential to global system sustainability.

Part of sustainable development discourses entail exploring alternative DRR subsystems as well as alternative CCA subsystems, namely finding or developing DRR or CCA subsystems that are more likely to be sustainable. They would be designed and assessed so as to take into account economic, socio-cultural, and political dimensions, thereby increasing systemic chances of medium to long-term sustainability.

Acknowledgments: We are grateful to Ilan Kelman for his comments and suggestions about earlier versions of this work. We also wish to thank the three anonymous reviewers for their constructive criticisms and suggestions. 
Author Contributions: Tom R. Burns has developed the sustainable development conceptualization. Burns and Nora Machado together contributed to the analyses and conclusions concerning DRR and CCA. They both wrote and formatted the paper.

Conflicts of Interest: The authors declare no conflict of interest.

\section{References and Notes}

1. Burns, T.R. Sustainable development: Agents, systems and the environment. Curr. Sociol. 2016, 64, 875-906.

2. World Commission on Environment and Development. Our Common Future; Oxford University Press: London, UK, 1987.

3. Drummond, I.; Marsden, T. Sustainable Development: The Impasse and beyond from the Condition of Sustainability; Routledge: London, UK, 1999.

4. Goodland, R. The concept of sustainable development. Annu. Rev. Ecol. Syst. 1995, 26, 1-24.

5. Opschoor, J.; van der Straaten, J. Sustainable development: An institutional approach. Ecol. Econ. 1993, 7, 203-222. Available online: www.geocities.ws/saxifraga_2000/costanza.doc (accessed on 10 December 2016).

6. WWF Global. Living Planet Report 2002; WWF International: Gland, Switzerland, 1996.

7. Baker, S. The Evolution of EU Environmental Policy: From Growth to Sustainable Development. In The Politics of Sustainable Development: Theory, Policy and Practice within the European Union; Baker, S., Kousis, M., Richardson, D., Young, S.C., Eds.; Routledge: London, UK, 1996.

8. Lafferty, W.M. The implementation of sustainable development in the European Union. In Contemporary Political Studies; Lovenduski, J., Stanyer, J., Eds.; PSA: Belfast, Northern Ireland, 1995.

9. UNISDR. Living with Risk: A Global Review of Disaster Reduction Initatives, Terminology on Disaster Risk Reduction; UNISDR: Geneva, Switzerland, 2004.

10. McCarthy, J.J.; Lanziani, O.F; Leary, N.A.; Dokken, D.J.; White, K.S. IPCC Climate Change 2001: Impacts, Adaptation, and Vulnerabillity; Cambridge University Press: Cambridge, UK, 2001.

11. Harris, J.M. Basic principles of sustainable development. In The Encyclopedia of Life Support Systems; UNESCO: Paris, France, 2001.

12. Burns, T.R. The Sociology of Complex Systems: An Overview of Actor-Systems-Dynamics. World Futures: J. Gen. Evol. 2006, 62, 411-460.

13. Burns, T.R.; Baumgartner, T.; DeVille, P. Man, Decision and Society; Gordon and Breach: London, UK, 1985.

14. Burns, T.R. System Theories. In The Blackwell Encyclopedia of Sociology; Blackwell Publishing: Oxford, UK, 2006.

15. Baumgartner, T.; Burns, T.R.; DeVille, P. The Shaping of Socio-economic; Systems: The Application of the Theory of Actor-System Dynamics to Conflict, Social Power, and Economic Innovation in Economic Life; Routledge: London, UK, 2014.

16. Burns, T.R.; Hall, P. The Meta-power Paradigm: Causalities, Mechanisms, E Constructions; Peter Lang: Frankfurt, Germany; Berlin, Germany; Oxford, UK, 2012.

17. Burns, T.R.; Machado, N. Technology, Complexity, and Risk: Part I: Social Systems Analysis of Risky Sociotechnical Systems and the Likelihood of Accidents. 2009. Available online: http://uu.divaportal.org/smash/get/diva2:685825/FULLTEXT01.pdf (accessed on 15 February 2017).

18. UNISDR. Terminology on Disaster Risk Reduction; UNISDR: Geneva, Switzerland, 2009.

19. Smith, K.; Petley, D.N. Mass Movement Hazards Environmental Hazards Assessing Risk and Reducing Disaster; MPG Books Ltd.: Bodmin, UK; Routledge: London, UK, 2009.

20. Carson, M.; Burns, T.R.; Calvo, D. Public Policy Paradigms: Theory and Practice of Paradigms Shifts in the EU; Peter Lang: Frankfurt, Germany; Berlin, Germany; Oxford, UK, 2009.

21. Carson, R. The Silent Spring; Houghton Mifflin: Boston, MA, USA, 1962.

22. Lundqvist, L. Planning for Climate Change Adaptation in a Multi-level Context: The Gothenburg Metropolitan Area. Eur. Plan. Stud. 2016, 24, 1-20.

23. Thörn, P.; Bonnier, E.; Roth, S. Klimatampassning (Climate Adaptation) 2016-Sålaingt har Sveriges kommuner kommit. 2016. Available online: http:/www.ivl.se/download/18.29aef808155c0d7f0504f1/1472806321253/ B2261.pdf (accessed on 10 December 2016).

24. Pelling, M. Adaptation to Climate Change: From Resilence to Transformation; Routledge: London, UK, 2011.

25. Blaikie, P.; Cannon, T.; Davis, I.; Wisner, B. At Risk: Natural Hazards, People's Vulnerability, and Disasters, 2nd edition; Routledge: New York, NY, USA, 2004. 
26. Kelman, I.; Gaillard, J.C. Embedding Climate Change Adaptation within Disaster Risk Reduction. In Climate Change Adaptation and Disaster Risk Reduction: Issues and Challenges; Shaw, R., Pulhin, J.M., Pereira, J.J., Eds.; Emerald: Bingley, UK, 2010; pp. 23-46.

27. They overlap. CCA relates to DRR [23] in the sense that climate change may engender disaster risks such as rising sea waters submerging low-lying islands or new disease vectors emerging to threaten populations of people and animals (for instance, the substantial change in weather conditions and expansion of ticks in the Baltic islands as temperatures rise and local climate conditions change). An appropriate CCA system under these conditions would include DRR components and mechanisms, that is, the DRRs are responses to climate change threats-of-disaster. But, obviously, many cases of DRR don't relate to climate change, and many climate changes don't entail disaster threats although they may be disruptive or aggravating.

(C) 2017 by the authors; licensee Preprints, Basel, Switzerland. This article is an open access article distributed under the terms and conditions of the Creative Commons by Attribution (CC-BY) license (http://creativecommons.org/licenses/by/4.0/). 